\title{
TENSIONAMENTOS NARRATIVOS NA COBERTURA JORNALÍSTICA DE BARÃO DE COCAIS (MG)
}

\author{
Narrative tension in the news coverage of Barão de Cocais (MG)
}

Tensión narrativa en la cobertura periodística de Barão de Cocais (MG)

André Luís Carvalho

Professor da Universidade Federal de Ouro Preto (UFOP) adlcarvalho@gmail.com

Karina Gomes Barbosa Professora da Universidade Federal de Ouro Preto (UFOP) karina.barbosa@gmail.com

Marta Regina Maia

Professora do Programa de Pós-Graduação da Universidade Federal de Ouro Preto (UFOP) marta@martamaia.pro.br

\section{Resumo}

O estado de Minas Gerais, Brasil, passou por dois acontecimentos relevantes em quatro anos: os rompimentos da Barragem do Fundão, em 2015, e da Mina Córrego do Feijão, em 2019. No rastro dessas ocorrências, a cidade de Barão de Cocais vive, desde maio de 2019, momentos de instabilidade com a iminência - anunciada pela mineradora Vale - do rompimento do talude da mina de Gongo Soco. A partir desse acontecimento, problematizamos a cobertura jornalística inicial de dois jornais mineiros, percebendo os tensionamentos entre as narrativas da mineradora e as das comunidades de Barão, tendo como metodologia a análise das marcas da apuração e da composição das matérias, considerando, por fim, que a cobertura privilegiou as informações da Vale, configurando sua hegemonia discursiva.

Palavras-chave: Catástrofe. Gongo Soco. Hegemonia discursiva.

\begin{abstract}
Minas Gerais State, Brazil, went through two relevant events in four years: the disruptions of the Fundão Dam in 2015 and The Córrego do Feijão Mine in 2019. In the wake of these occurrences, Barão de Cocais city lives, since May 2019, unstable moments by the Vale mining company announcement about the embankment rupture of the Gongo Soco mine. From that event we are questioning the initial journalistic coverage of two newspapers from Minas Gerais realizing the tension between the narratives of the mining company and those of the communities of Barão, using as methodology the analysis of the marks of the investigation and the composition of the articles, considering, finally, that coverage privileged Vale's information, configuring its discursive hegemony.
\end{abstract}

Key words: Catastrophe. Gongo Soco. Discursive hegemony. 


\section{Resumen}

El estado de Minas Gerais, Brasil, pasó por dos eventos relevantes en cuatro años: las interrupciones de la represa Fundão en 2015 y la mina Córrego do Feijão en 2019. A raíz de estos hechos, la ciudad de Barão de Cocais vive, desde mayo de 2019, momentos de inestabilidad con la inminencia, anunciada por la compañía minera Vale, de la ruptura del terraplén de la mina Gongo Soco. A partir de ese evento, problematizamos la cobertura periodística inicial de dos periódicos de Minas Gerais, dándonos cuenta de la tensión entre las narrativas de la compañía minera y las de las comunidades de Barão, utilizando como metodología el análisis de las marcas de la investigación y la composición de los artículos, considerando, finalmente, esa cobertura privilegió la información de Vale, configurando su hegemonía discursiva.

Palabras clave: Catástrofe. Gongo Soco. Hegemonía discursiva.

\section{INTRODUÇÃO}

Minas Gerais, um dos maiores estados do país, passou por dois acontecimentos relevantes no cenário nacional em pouco mais de três anos: os rompimentos da Barragem do Fundão, da mineradora Samarco (Vale/BHP Billiton), em 5 de novembro de 2015, e da Mina Córrego do Feijão, também da Vale, em 25 de janeiro de 2019. No rastro dessas duas catástrofes, com a morte e desaparecimento de quase 300 pessoas e danos irreversíveis às comunidades atingidas e ao meio ambiente, a cidade de Barão de Cocais vive, desde fevereiro de 2019, momentos de instabilidade e tensão com a iminência - anunciada pela própria Vale do rompimento do talude da mina de Gongo Soco, que poderia colapsar a barragem adjacente. Pode-se tratar de uma "catástrofe falhada, cuja potência se assemelha à da arte - iminência de um acontecimento total que não se dá mas que anuncia por isso mesmo o arco da vida inteira, chicoteando-a de luz" (WISNIK, 2018, p. 29).

A Defesa Civil do Estado, a partir da experiência do rompimento das duas barragens citadas, considerou pertinente a realização de simulações com a população de Barão de Cocais para reduzir os danos em função do risco iminente de ruptura da Gongo Soco. Essas simulações foram realizadas com os moradores da chamada (pelas autoridades) "zona secundária" de salvamento (que compreende cerca de 6 mil moradores), visto que os 443 moradores da zona de autossalvamento foram retirados de suas residências em fevereiro de 2019, quando o nível de segurança atingiu o nível 2. O alerta máximo de rompimento ocorre 
no nível 3. Passados mais de dois anos, as famílias não voltaram para suas casas e continuam vivendo de maneira inconstante, morando em imóveis alugados pela Vale ${ }^{1}$.

A situação de instabilidade gera um clima de crise para os moradores que têm o futuro incerto. De acordo com o prefeito da cidade, Décio Geraldo dos Santos (PV), o hospital público funcionou com sua capacidade máxima de lotação após o anúncio da possibilidade do rompimento: "Nós não tivemos morte na lama [...] Infelizmente, nossos irmãos de Brumadinho não tiveram tempo de fazer o que a gente está fazendo aqui [...] No entanto, estamos tendo mortes de várias outras maneiras: depressão, estresse, tentativa de suicídio" (FERREIRA, 2019). A cidade registrou 6 mil atendimentos a mais em relação ao mesmo período do ano anterior.

A partir desse último acontecimento, e da catástrofe como potência e ameaça, pretendemos problematizar a cobertura jornalística de dois jornais mineiros entre os três de maior circulação no estado, $O$ Tempo e Estado de Minas $(E M)^{2}$, tendo como instância prioritária de análise perceber os tensionamentos entre as narrativas da mineradora e as das comunidades de Barão, avaliando se há alguma hegemonia discursiva configurada pela cobertura.

\section{ACONTECIMENTO E TEMPORALIDADES}

Assistimos, de maneira cada vez mais frequente, à discussão sobre o papel do acontecimento na existência social e quais seriam as instituições, meios ou formas que produzem sentidos a partir de certas ocorrências. Sabemos que os acontecimentos rompem com a normalidade, afetam situações e sujeitos, já que envolvem uma dimensão relacional (FRANÇA, 2012; QUERÉ, 2012) e ainda "convocam um passado e re-posicionam o futuro" (FRANÇA, 2012, p. 14).

Enquanto a maioria dos acontecimentos que emerge midiaticamente, aos quais estamos habituados, costuma representar uma ruptura indelével com a normalidade, transformando-se em discurso, a crise de Barão de Cocais representa um fato concreto com

1 Reportagem do G1 de julho de 2021 relata a continuação das audiências de negociação entre a Vale e o município, ainda sem desfecho, em meio a avanços lentos e reclamações das comunidades. Os moradores de locais evacuados, como a comunidade de Socorro demandam o retorno ao território, que ainda não havia acontecido até agosto de 2021, apesar de a mineradora já ter anunciado o descomissionamento da estrutura. Disponível em: https://g1.globo.com/mg/minas-gerais/noticia/2021/07/02/audiencia-discute-situacao-debarao-de-cocais-por-causa-de-risco-de-barragem-da-vale.ghtml. Acesso em 24 ago. 2021.

2 Segundo dados do IVC de 2018, o EM é o sexto jornal de maior circulação no país e o jornal $O$ Tempo o $24^{\circ}$. 
tangibilidade distinta - lá, o que configura o acontecimento das catástrofes minerárias brasileiras como Fundão e Córrego do Feijão ainda não se deu, visto que não houve rompimento. Mas, ainda assim, algo aconteceu. Ursula Le Guin nos lembra que acontecimentos “deixam uma marca atrás de si” (2018, p. 21). Conforme Queré:

[...] a principal distinção que nós podemos fazer é entre os acontecimentos como mudanças que se produzem concretamente em nosso meio ambiente e os acontecimentos como objetos (objetos de pensamento, de discurso, de investigação, de julgamento). A grande diferença entre as duas formas é a simbolização, que introduz na experiência uma dimensão diferente daquela da simples existência (embora, como veremos, ela não esteja ausente da última). (QUERÉ, 2011, p. 3-4)

Ainda sobre uma catástrofe que não se deu, vale destacar as diversas temporalidades aqui suscitadas por um outro acontecimento por se dar, em suspensão. São vários tempos que aqui se cruzam, se confrontam no anúncio contínuo, ininterrupto, sem trégua, ao menos na visão de quem o vive, o sente na pele (os moradores de Barão de Cocais), e que complexifica ainda mais a ruptura temporal trazida pelo evento traumático. Os estrondos altos, fortes, repentinos, inesquecíveis, instantâneos, de curta duração no tempo cronológico, e longa ou persistente nas narrações do trauma pelos testemunhos dos sobreviventes da Mariana e Brumadinho, são para os moradores de Barão Cocais apenas potências.

Não são, do ponto de vista formal, vítimas que sucumbiram ao acontecimento catastrófico, ou sobreviventes, que dele puderam escapar. São ex-moradores se sua cotidianidade for definitivamente destruída pelos rejeitos, ou moradores temporários de um outro lugar provisório, onde agora habitam sabe-se por lá por quanto tempo. Ou seja, tais processos disruptivos na vida cotidiana desses sujeitos projetam sentidos sobre a situação e configuram possibilidades (QUERÉ, 2005). Imprimem um estado do "entre eterno", por não serem, em definitivo, nada que caracterize um evento desta natureza ou habitante de seus tempos. Vivem um entre espaço e entre tempo, diariamente deslocados. O tempo estreito das sirenes que tocam e do prazo para sobreviverem, da imprevisibilidade do que está por vir. O tempo da memória das catástrofes recentemente ocorridas em Minas, seus sons e imagens mostrados pela mídia. O tempo das simulações e de toda sua tensão, sua previsibilidade calculada. O tempo estendido de um presente e futuro incertos.

Evidenciamos ainda, nessa perspectiva, uma forma de (re)organização social, que conecta espaço e tempo, dado que o acontecimento promoveu deslocamentos geográficos, alterando relações identitárias, instaurando um estado de tensão permanente em seus cotidianos, reforçado por planos e simulações de evacuação, rotas de fuga, marcações de áreas 
de risco, que reconfiguram a cidade que habita(va)m. Quem nos ajuda a refletir sobre esse aspecto é Manuel Castells (1999), que apresenta os modos coletivos de constituição das identidades na atualidade: "a construção de identidades vale-se da matéria-prima fornecida pela história, geografia, biologia, instituições produtivas e reprodutivas, pela memória coletiva e por fantasias pessoais, pelos aparatos de poder e revelações de cunho religioso" (p. 23). Na medida em que as pessoas perderam total ou parcialmente seus lastros comunitários e de identificação, as relações começaram a sofrer esgarçamentos que dificultam os processos de sociabilidade anteriormente instituídos pela convivência.

\section{NARRATIVAS JORNALÍSTICAS SOBRE A “IMINENTE" CATÁSTROFE}

Consideramos o jornalismo como um dos espaços proeminentes de produção de sentidos na atualidade. Entretanto, ao tomarmos o jornalismo como objeto de estudo não estamos desconsiderando outras mediações presentes na sociedade, como a religião, a escola e a família, por exemplo. Compreendemos que ele não está desvinculado das instituições e do contexto político e econômico nacional. E é a partir dessa perspectiva que observamos alterações no modus operandi da prática jornalística; antes sustentada pelas redações organizacionais e hoje bem mais fluída, com o advento dos free lancers, da precarização do trabalho e de outros modos de produção noticiosa. Concordamos com Deuze e Witschge quando definem "o jornalismo contemporâneo como um conjunto bastante complexo e desenvolvido de atitudes e práticas de (grupos ou equipes de) indivíduos envolvendo tanto jornalistas profissionais quanto profissionais de áreas afins, como programadores, designers e profissionais de marketing" (2016, p. 8).

Esse movimento de ampliação do campo contribui para a complexificação das narrativas jornalísticas, antes mais voltadas para o presente, e que hoje consideram também o passado e o futuro como elementos de composição de suas histórias. Ao discutir a relação entre jornalismo e memória, Tenenboim-Weinblatt (2014) reflete sobre as formas de engajamento do público nas narrativas jornalísticas que retomam o passado (e até mesmo o futuro) como um recurso narrativo bastante produtivo e agenciador ao conectar "informação, rituais e agenda setting, assim como memorações retrospectivas e prospectivas” (p. 109, tradução nossa). Essa espécie de ampliação do caráter temporal das informações pode garantir o agenciamento do leitor às narrativas produzidas.

Assim como discordamos do conceito de história, ciência próxima a nossa área, como estudo essencialmente do passado, posto que a história é sempre produzida na própria época 
do historiador (BARROS, 2013), traduzimos essa discussão para o jornalismo, discordando de sua visão instrumental - enquanto abordagem exclusiva do presente -, visto que as narrativas jornalísticas são sempre acionadas na conjunção entre presente, passado e futuro. Consideramos então o jornalismo como o espaço de configuração das histórias dos sujeitos e acontecimentos no tempo, oferecendo condições para o estudo crítico das coberturas.

Louis Queré (2012) também nos ajuda a compreender o processo de produção desse tipo de narrativas ao dizer que "o passado se modifica porque o presente passa por mudanças: um presente diferente faz surgir um passado diferente" (p. 27). No caso dos relatos em questão, os de catástrofes, avaliamos que os tensionamentos acontecem por conta de acontecimentos de ampla reverberação social e com desdobramentos ainda insolúveis. Como essas ocorrências ganham vida por intermédio dos meios de comunicação, questionamos, assim como Ana Cláudia Peres: “Até que ponto o jornalismo é, também, testemunho?” (2016, p. 94). Para a autora, mais do que prática ou discurso, o jornalismo é "gesto relacionado à comunicabilidade da experiência" (p. 102) e, nesse sentido, também pode ocupar esse lugar do testemunho ao ouvir e escutar os sujeitos envolvidos em situações desse porte, não como apenas como presumida (CASADEI, 2010) ou instrumento de objetividade (LAGE, 2013).

Destarte, não queremos corroborar uma ideia de jornalismo autônomo, sem vínculos ao sistema que o mantém, mas como instituição que é composta também por sujeitos. Avaliamos seu caráter como contraditório, em especial quando é acionado por repórteres que estiveram presentes em locais de conflitos e catástrofes.

Se consideramos a narrativa como "modo de apreender o mundo, de dar sentido à vida" (LEAL, 2013, p. 29) é porque reconhecemos que os significados oferecidos pelos meios indicam formas de compreensão do mundo que nos cerca. O que implica, nos termos de Roger Silverstone (2005) a emergência e a necessidade de se estudar a mídia. Ela, que se constitui como condutora de ideias, como linguagem e ainda com um ambiente que açambarca nossa vivência cotidiana (SILVERSTONE, 2005), está presente de maneira expressiva e significativa em nossa experiência social.

Então, entre o acontecimento e o público muitas camadas se interpõem. Para Maurice Mouillaud (2012) o jornal, enquanto dispositivo, não serve apenas para circunscrever a notícia, ele pode conferir processos de significação e criar expectativas de leituras, o que garante a ele um papel relevante (mas não único) nas formas de representação da realidade. Como já dito, o acontecimento referente ao deslocamento de centenas de pessoas de Barão de Cocais e a iminência do rompimento da barragem que poderia afetar milhares de pessoas no 
entorno foi destaque em vários meios de comunicação em todo país em 2019. Essa visibilidade narrativa, entretanto, não é homogênea e precisa ser estudada, dada a importância da mídia como ponto de referência para nossas vidas. A partir dessa perspectiva, passaremos então para a análise das matérias dos jornais mineiros.

\section{MARCAS DE APURAÇÃO E EDIÇÃO DA COBERTURA}

Temos como base o protocolo metodológico de análise de coberturas jornalísticas em textos impressos proposto por Gislene Silva e Flávia Maia (2011), que parte do pressuposto que decisões editoriais deixam marcas no produto, "no acontecimento publicado" (p. 22). Silva e Maia dizem que tal método busca observar as estratégias de cobertura expressas no material jornalístico (p. 25) - e, complementamos, evidenciar como são conformadas as hegemonias discursivas nas narrativas jornalísticas por meio dessas marcas, que incluem caminhos percorridos pelos/as jornalistas e pelos veículos no processo de apuração. Recusamos, portanto, uma visada esquemática que analisa o circuito comunicativo a partir de lugares definidos e fragmentados; optamos pela perspectiva comunicacional enquanto processo.

Da série de aspectos técnicos do processo produtivo que podem ser explicitados, focalizamos o primeiro e o último elencados por Silva e Maia: as fontes de informação consultadas e o predomínio de fontes oficiais. A elas acrescentamos a produção de imagens fotográficas. Por meio de um instrumento de coleta quanti-qualitativo, organizamos as informações atentando-nos, especialmente, ao primeiro nível, as marcas de apuração, e ao segundo nível, as marcas de composição do produto.

Debruçamo-nos sobre 14 matérias - oito do Estado de Minas e seis d'O Tempo, entre 27 de maio e 3 de junho de 2019. O período corresponde ao ápice da iminência do rompimento da barragem Sul Superior, da mina Gongo Soco, a partir do desabamento do talude, quando notícias diárias davam conta do avanço da movimentação da estrutura. No $E M$, foram três matérias de página inteira e outras três em que a cobertura divide espaço com outros assuntos relacionados às tragédias da mineração. $O$ Tempo também dedicou três páginas inteiras ao acontecimento, e uma matéria divide espaço com assuntos relacionados. Os dois jornais enviaram à região mais de um repórter e fotógrafos/as (não simultaneamente) e contaram também com repórteres baseados na capital mineira, o que evidencia a importância dada ao acontecimento pelos veículos, assim como a abordagem em página inteira, muitas delas com retrancas, infográficos e quadros. 
Do total de matérias analisadas, 12 ouvem fontes testemunhais, e 10 ouvem fontes da Vale, mineradora responsável pela mina Gongo Soco. Todas as matérias d'O Tempo têm fontes testemunhais, enquanto no $E M$ duas não trazem. O $E M$ deixa de trazer a Vale em três matérias e $O$ Tempo, em uma. A maioria das matérias, 50\%, traz 2 fontes testemunhais, enquanto $41 \%$ apresentam 1 fonte da empresa. Destacam-se também as fontes do poder público, notadamente a Defesa Civil (presente em 9 matérias) e a Agência Nacional de Mineração (ANM), presente em 7. Importante ressaltar que a Coordenadoria Estadual de Defesa Civil (Cedec) foi ouvida em quase todos os casos a partir de um sujeito: no EM o subcomandante da Cedec, Flávio Godinho, e n'O Tempo o comandante Marcos Pereira. Esse recurso às fontes governamentais por parte dos veículos demonstra o acesso que os/as repórteres têm ao órgão. Já no caso da ANM o aparecimento se dá, sobretudo, institucionalmente, sem vozes que encarnem a posição da agência.

\section{FALAR MAIS, SER MENOS OUVIDOS/AS}

Apesar do predomínio objetivo de vozes testemunhais nas matérias analisadas, o olhar qualitativo sobre o material deixa claro que é o discurso técnico-corporativo que predomina na cobertura. As matérias que ouvem sujeitos de Barão de Cocais, atingidos pela iminência de uma catástrofe, não os trazem como centro da apuração, mas apenas dentro da lógica das fontes jornalísticas de informação (LAGE, 2013), um "artifício retórico fundado numa pretensão à veracidade própria do jornalismo" (p. 75). Nesse sentido, tratam-se mais e apenas de atestações do sofrimento e menos aquilo que se costuma chamar de testemunho midiático, ou seja, um testemunho mediado pela instância da mídia. Para Lage, “a presença dos indivíduos enquanto testemunhas é narrativamente construída, ou seja, é verbal e visualmente configurada no curso do relato jornalístico" (p. 81).

Em muitas matérias, o texto jornalístico apresenta os sujeitos atingidos de forma difusa, como "os moradores aproveitam a missa de domingo para pedir proteção" (PARREIRAS, 2019, p. 14), para, em seguida, singularizar um desses moradores: “Nas nossas orações, estamos pedindo que Deus tenha misericórdia de nós', disse a dona de casa Andreia Aparecida Chaves" (Idem, ibidem). Essas marcas testemunhais aparecem apenas no último dos seis parágrafos da matéria de página inteira, que tem o título dedicado aos sujeitos, mas não os torna protagonistas da narrativa: "Dia de vigília e orações" (Figura 1). Todo o resto da página explica a situação do talude da mina e as medidas tomadas para reverter a crise. 
Figura 1: $E M, 27$ de maio

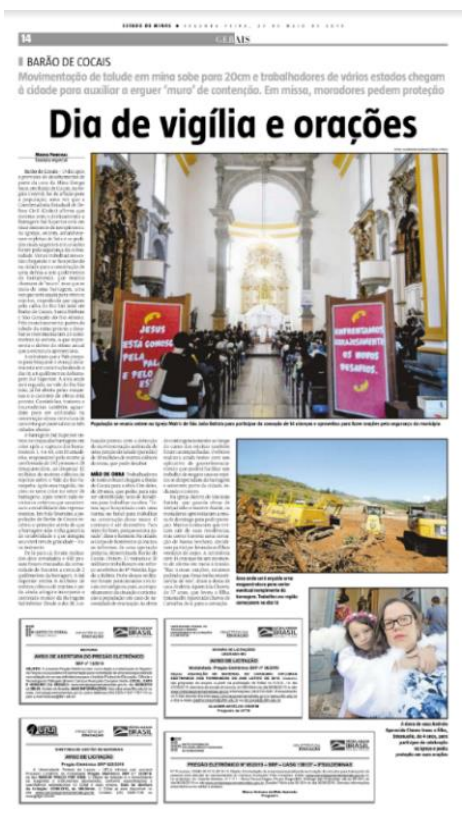

Fonte: Acervo do jornal
Figura 2: $O$ Tempo, 30 de maio

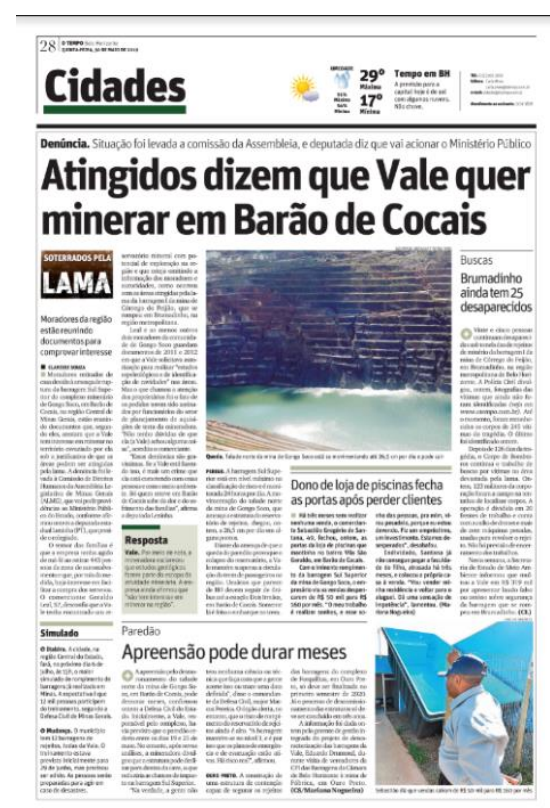

Fonte: Acervo do jornal

A mesma construção discursiva fica evidenciada na narrativa d'O Tempo. A matéria "Atingidos dizem que Vale quer minerar em Barão de Cocais" (Figura 2) começa informando que "moradores retirados de casa devido à ameaça de ruptura da barragem Sul Superior do complexo de Gongo Soco [...] estão reunindo documentos que, segundo eles, atestam que a Vale tem interesse em minerar no território esvaziado por ela [...]” (SOUZA, 2019, p. 28) para, em seguida, trazer a fala de um morador, acompanhada das declarações de uma deputada estadual, que divide com os atingidos o protagonismo na matéria. Apenas na retranca "Dono de loja de piscinas fecha as portas após perder clientes" o protagonismo narrativo é dado, no pequeno texto de três parágrafos, a um sujeito - que, no entanto, aparece de costas na imagem que acompanha a notícia. Ou seja, se o testemunho é algo único, em razão da experiência particular de quem vive um acontecimento extremo, nesse caso a identidade desse potencial sobrevivente, aquele que pode testemunhar, é suprimida da fotografia.

Em outra matéria d'O Tempo, dois sujeitos aparecem em destaque na imagem central da página, mas a matéria principal, “Após alerta máximo, Vale diz que chance de barragem ruir reduziu" (SOUZA, 2019, p. 21), não traz nenhuma fonte testemunhal, contando apenas com a fala de um representante da Vale e um especialista em engenharia. O teor testemunhal 
se evidencia apenas, novamente, em uma retranca, um quadro preto no canto inferior da página, intitulado “Acho que nada vai acontecer”, em que Edna de Souza, fotografada ao lado da mãe no centro da página, conta sua história.

O testemunho de sujeitos que estão à beira da catástrofe, vivendo entre tempos e entre lugares (físicos e discursivos) fica em segundo plano também na matéria "Tentativa de retomar a rotina" (MENEZES, 2019, p. 22). A matéria ocupa $3 / 4$ da página (Figura 3), e nos primeiros quatro parágrafos a narrativa dominante é a institucional, relativa à prefeitura do município. A primeira fonte testemunhal fora ouvida pela reportagem dias antes da publicação do texto. Apenas no intertítulo "Trauma" abre-se a possibilidade, não concretizada, de um testemunho que extrapole o registro de experiência, quando uma mãe narra, em dois parágrafos, o sofrimento do filho. Na retranca "Alunos apresentam transtornos" o assunto é retomado, na fala de uma professora. Os alunos traumatizados estão ausentes.

Figura 3: $O$ Tempo, 2 de junho

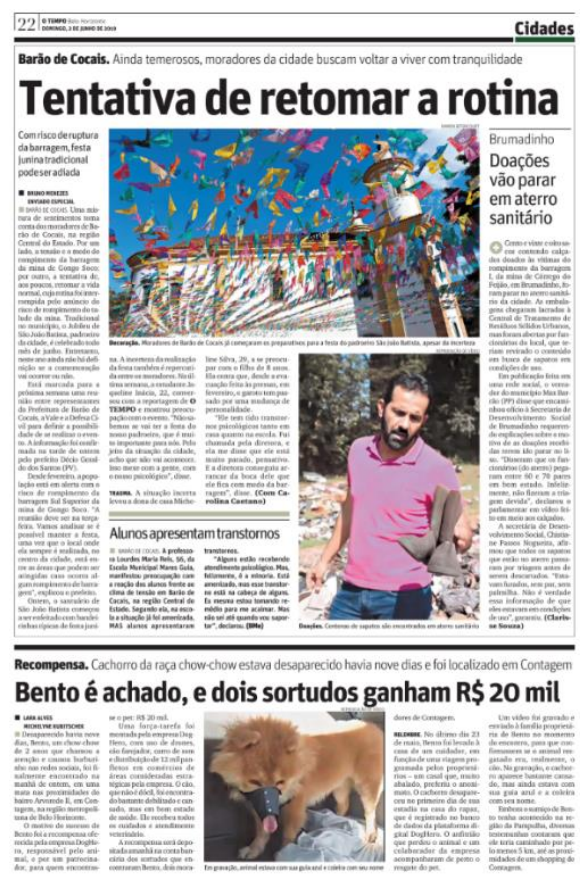

Figura 4: $E M, 30$ de maio

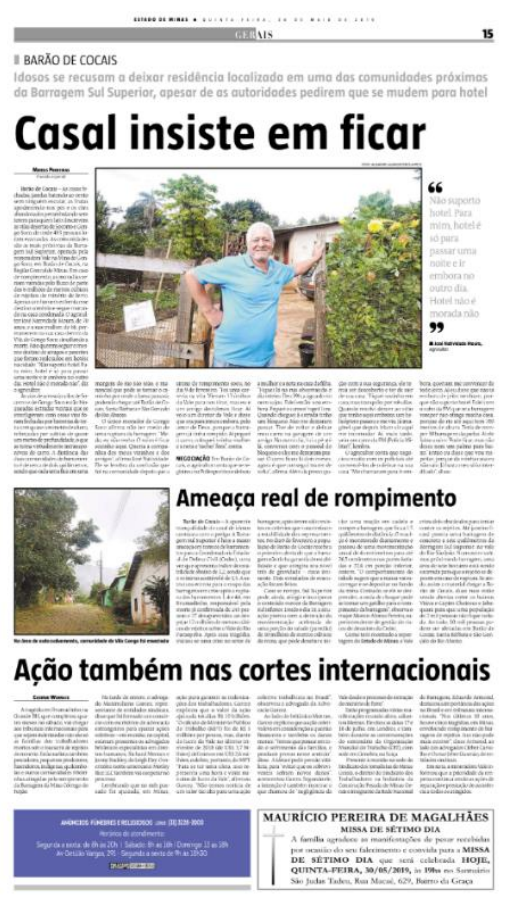

Fonte: Acervo do jornal

Fonte: Acervo do jornal

A matéria "Casal insiste em ficar" (PARREIRAS, 2019, p. 15), do EM, é uma das poucas que modifica essa relação (Figura 4). Aqui, o teor testemunhal da experiência de José 
Natividade Moura é protagonista da narrativa jornalística. Ele é a única fonte ouvida no texto principal, e narra os acontecimentos das últimas semanas sob seu ponto de vista, que em momento algum é confrontado ou mediado por outros discursos ou fontes. Essa história, porém, ocupa a metade superior da página; o resto traz uma retranca de recapitulação técnica, onde o EM lembra a situação do talude e as medidas tomadas para evitar a catástrofe, e uma matéria sobre ações judiciais em cortes internacionais relativas a Brumadinho.

Na matéria "Distritos sentem impacto de obras" (RONAN, 2019, p. 15), que ocupa a metade inferior de uma página, os cinco primeiros parágrafos trazem narrativas dos sujeitos atingidos. No sexto parágrafo, o jornal informa que a Vale "não se manifestou sobre as queixas de moradores locais" (Idem, ibidem), mostrando que, como na maioria das abordagens, o teor testemunhal necessita ser cotejado ou ancorado por fontes da empresa, a fim de garantir a prevalência do modelo de objetividade vigente no jornalismo hegemônico; como afirma Lage, nessa perspectiva, "o testemunho equivaleria ao simples registro de uma experiência” (2013, p. 77), que não se sustenta sem a contrapartida do discurso técnicocorporativo, evidenciado pelas fontes de órgãos do governo - notadamente Defesa Civil e ANM, como dito - e pela empresa.

Mesmo quando a Vale não é ouvida - ou se recusa a prestar esclarecimentos - a sombra da mineradora se espraia pelas narrativas do acontecimento, como se ela controlasse a catástrofe iminente. O lugar ocupado pela Vale de fonte primária do deslocamento do talude fica evidenciado na matéria d'O Tempo "Parte de talude que caiu é menos de $1 \%$ de paredão que se move" (SOUZA, 2019, p. 22), quando o texto informa que "a Defesa Civil confirmou a

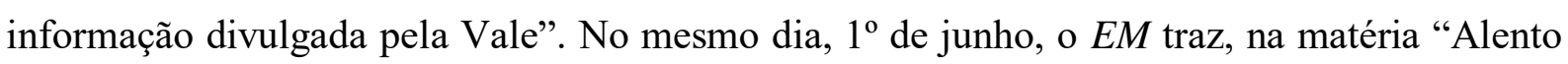
depois do susto" (RONAN; SILVA, 2019, p. 14), a fala do tenente-coronel Flávio Godinho, da Defesa Civil, que atua como fonte de segunda mão da mineradora: "Foi um desprendimento de uma parte insignificante, segundo a Vale [...]”.

O discurso técnico-corporativo estabelece sua hegemonia narrativa a partir de longas explicações dadas, a cada matéria, sobre o processo vivenciado pelo talude - e não pelos sujeitos atingidos em Barão de Cocais. A migração forçada, a tensão, o trauma, a paralisação da rotina, a expropriação de terras, são temas secundários em relação à descrição e aos esclarecimentos didáticos sobre os processos técnicos que ocorrem na cidade. Mesmo quando temas centrados na perspectiva dos sujeitos das catástrofes são abordados, como na matéria "Moradores fogem de Barão, e bombeiros ficam em alerta", d'O Tempo, o sujeito atingido 
surge em apenas dois parágrafos. A abertura da matéria reforça o discurso técnico e esvazia a tragédia de seus protagonistas humanos:

O clima em Barão de Cocais, na região Central de Minas, era de muito medo e tristeza ontem, dia previsto pela mineradora Vale para a queda do talude norte da barragem Sul Superior da mina de Gongo Soco [...] Na sexta-feira, o deslocamento alcançava $16 \mathrm{~cm}$ por dia. A Vale informou às autoridades sobre o problema no último dia 13, quando a movimentação era de $4 \mathrm{~cm}$ por dia. A preocupação é que o desabamento da estrutura, que dá sustentação à mina, leve ao rompimento da barragem. (FERREIRA, 2019, p. 22)

É mais uma evidência de como a máquina minerária (WISNIK, 2018) que opera em Minas Gerais invisibiliza os sujeitos que a colocam para operar e sofrem as consequências de sua sanha exploratória e extrativista. Em diversas matérias, os/as repórteres explicam o que é uma cava, um talude, descrevem os barramentos e as dimensões da catástrofe; além do uso constante de vocábulos técnicos como estrutura, estabilidade, autossalvamento - em contraposição a expressões como atingidos, trauma, rotina, que demarcam o lugar dos sujeitos na narrativa jornalística, e que têm presença menor na cobertura. N'O Tempo, um infográfico de meia página detalha, em 27 de maio, as possíveis consequências do rompimento do talude. No EM, uma estratégia comum são blocos repetidos de textos entre matérias com a contextualização técnica básica do acontecimento.

Pensando nas imagens que constroem este acontecimento jornalístico, das oito edições do EM, em apenas uma, de 30 de maio, aparece o retrato de uma vítima direta, claramente nomeada e descrita como tal. Trata-se da particularização de José Natividade Moura como personagem (Figura 4), de forma mais íntima e destacada. No restante do campo expressivo desta imagem, está parte de sua casa em Gongo Soco, região que fora totalmente esvaziada por medida de segurança, em caso de rompimento do talude. Segundo a matéria, apenas ele e sua esposa (que não é nomeada) preferiram ficar no local, apesar do risco.

Essa é a única foto que possui como legenda a fala de um morador. Transformada em olho da notícia, e tendo, portanto, destaque ampliado, a legenda diz: "Não suporto hotel. Para mim, hotel é só para passar uma noite e ir embora no outro dia. Hotel não é morada não" (PARREIRAS, 2019, p. 15). No semblante, um sorriso, uma pose confortável, tranquila, certa da decisão, que o coloca e a sua esposa em um estado de resistência, de imobilidade diante do que pode ocorrer - não aceita ser deslocado. Na fala, um protesto, um anúncio de tempo futuro, quase uma premonição, que denuncia o tempo incontável e impreciso de ser deslocado e forçado a fazer de um hotel, local de trânsito, sua morada. 
Morada é uma palavra cara ao pensamento derridiano (DERRIDA, 2015) sobre trauma e testemunho, especialmente quando o autor analisa Maurice Blanchot. Para quem viveu o trauma e o testemunha, é um lugar sempre em trânsito: do que foi a experiência quase indescritível da destruição, do que é agora esse lugar do sobrevivente diante do mundo, de reconfigurar todas estas vivências, memórias, experiências quase irreconciliáveis. Mas e para quem não experimentou uma tragédia, ainda iminente? Para quem vive, de forma espectral ou fantasmática, o que ainda não ocorreu mas que já o desloca de seu lugar seguro, assim como quem passou por um evento traumático é deslocado incessantemente, o que pode ser essa morada?

As duas outras referências imagéticas feitas pelo $E M$ às pessoas atingidas por esse estado de alerta não as individualizam, ou as colocam como sobreviventes de uma tragédia anunciada. Estar nesse lugar de trânsito não representa uma forma de sobreviver ao medo, à dor de ter sua vida atravessada por uma catástrofe anunciada? Sob a manchete "Dia de vigília e orações", de 27 de maio, há três fotografias. A primeira, de uma igreja em que todas as pessoas aparecem de costas, com exceção do celebrante. A segunda em ordem de tamanho, posição e hierarquia mostra três máquinas pesadas no primeiro plano, com os indícios da obra que realizam (terra batida) e a serra ao fundo. E a última, com uma mãe e uma filha, mostra finalmente a face de moradores da região, embora não deixe claro se atingidas diretas ou não caso a barragem se rompa.

O surpreendente aqui é o fato de que mesmo com o mote da matéria sendo a iminência da catástrofe e o terror por ela impresso às pessoas atingidas, ao menos em potência, a primeira foto não destaca nenhum indivíduo; a segunda imagem destaca as máquinas sem mostrar muito, ou quase nada, do que elas fazem - pois estão quase sempre paradas; e a terceira, por fim, sequer cuida de trazer algum personagem que estivesse no local das orações. O que parece indicar uma invisibilização daqueles mais propensos ou condenados à catástrofe. E que nos faz desconfiar se são ou não vistos como vítimas, sobreviventes, em sua condição particular. Estar no tempo e no espaço entre a ocorrência e a iminência de uma tragédia torna seus habitantes menos passíveis de destaque na enunciação do evento traumático? E por fim, a grande e maior protagonista das imagens editadas para o $E M$, e muitas vezes confirmadas pelas manchetes e legendas de cada matéria, parece ser, ao menos pela recorrência, hierarquia e construção, a máquina - o trator, a retroescavadeira, parte também do maquinário da mineração brasileira - que impõe sua força e potência à narratividade de um acontecimento tão complexo. 
Já a narrativa visual d'O Tempo traz uma presença mais marcada, ainda que não dominante, dos sobreviventes dessa tragédia anunciada, ou de rastros, índices humanos mais destacados na maioria das imagens publicadas, como uma brecha, uma fissura discursiva, embora a narrativa textual pareça seguir o padrão do EM. Das sete páginas analisadas, em três, quase a metade, retratos de moradoras da cidade aparecem como principais fotografias, levando em conta a hierarquia visual estabelecida pela dimensão (maior foto) e posição (central e na parte superior) que ocupam. Em todas, são mulheres que relatam suas condições, nas edições de 26 e 27 de maio e $1^{\circ}$ de junho. Elas são nomeadas e fotografadas de frente, o que evidencia a importância de suas identidades. Contudo, seus testemunhos no texto são coadjuvantes, como já descrito.

Além delas, em 30 de maio, único dia em que $O$ Tempo usou uma fotografia do talude como imagem principal, há outra foto menor, no canto inferior direito, onde figura o único homem morador da cidade a testemunhar, durante o período analisado. Curiosamente, é o único retrato que não deixa ver a identidade do personagem, embora a legenda da foto e o texto da retranca da página o identifiquem: “o comerciante Sebastião Gregório de Santana, 49". A fotografia mostra o homem de costas, em um plano lateral que deixa ver apenas parcialmente seu rosto (Figura 2).

Em outros dois dias, 2 e 6 de junho, aparecem figuras públicas, também em fotos secundárias. No primeiro, o vereador da cidade, Max Barão (PP), em uma imagem vertical, na parte inferior da página, logo abaixo da foto principal, em que o santuário de São João Batista aparece todo decorado para a festa do padroeiro da cidade. O vereador segura um par de botas, no aterro sanitário da cidade, já que a matéria trata de uma contestação feita por ele a respeito de uma doação de sapatos que teria ido parar no lugar. No outro dia, aparece um pequeno retrato do governador de Minas Gerais, Romeu Zema, em sua primeira visita a Barão de Cocais.

Portanto, das sete páginas analisadas n'O Tempo, somente a do dia 21 de maio não apresenta imagens com algum personagem. Nela figuram uma foto do complexo da mina de Gongo Soco, transformada em infográfico para localizar o talude com risco de rompimento; e outra de uma unidade móvel do banco Bradesco na cidade. Nas demais páginas, algum personagem é identificado visualmente pelas fotografias, seja como fonte oficial ou testemunhal. E em quatro, ou seja, a maioria, há moradores vítimas do acontecimento. O que parece corroborar com a marca gráfica criada pel'O Tempo para identificar a cobertura: um 
retângulo marrom, em degrade, em que se se escreve o título "Soterrados pela Lama" (Figura 2), que nos leva a imaginar os sujeitos do acontecimento.

Curioso pensar que ninguém foi de fato "soterrado", mas vivem a iminência da consequência mais trágica do acontecimento, o rompimento. "Soterrado" destaca o estado de devastação das vidas postas em trauma, em medo constante, diante da iminente avalanche de rejeitos, comum e equivocadamente tachados de "lama" pela imprensa - talvez pela cor, pela estética, mas com certeza não pelo que contém, os rejeitos da máquina minerária predatória e devastadora.

Outro aspecto que chama a atenção nas fotografias destacadas de moradoras de Barão de Cocais é que em todas o plano de fundo são suas casas, mostradas externa ou internamente. Edna está em frente a uma casa aberta, de onde podemos ver parte do interior. Eva está sozinha sentada no sofá de casa. Marta Rodrigues aparece com uma senhora que pode ser sua mãe (nem a matéria nem a legenda nomeiam) com sua casa fechada ao fundo. A morada derridiana como lugar de trânsito em que presente, passado e futuro se alternam frequentemente marca essas imagens. A casa é abrigo, lugar seguro, história, memória, mas também fantasma de um futuro em potencial destruição. Assim, diferente do EM, O Tempo constrói sua narrativa visual a partir das fontes testemunhais e oficiais, mesmo que não dê a elas, no texto, um espaço de fala que condiga com o destaque das fotografias.

Se consideramos, como já falado, que a narrativa, de alguma maneira, configura-se como uma maneira de proporcionar sentido ao mundo que nos cerca, observamos que as fontes/personagens, nessas matérias, aparecem como coadjuvantes, destituídas de suas singularidades. Afinal se narrar "é estabelecer um modo de compreensão do mundo, de configurar experiências e realidades, de comunicar-se com o outro" (LEAL, 2013, p. 28), as notícias/reportagens analisadas representam muito mais que uma simples modalidade textual, elas traduzem perspectivas adotadas tanto no processo de captação e apuração quanto no processo de composição e edição do material publicado.

\section{CONSIDERAÇÕES FINAIS}

As catástrofes minerárias atingem Minas Gerais muito antes do rompimento da Barragem de Fundão, em 2015, mas se amplificam a partir das tragédias socioambientais que dizimaram o subdistrito marianense de Bento Rodrigues e a comunidade de Córrego do Feijão, em Brumadinho - para além de outras incontáveis consequências. Atrelado a essas catástrofes históricas que acompanham a máquina minerária como força motriz de um 
progresso capitalista técnico e desumanizante vem o silêncio midiático histórico sobre esses acontecimentos, rompido à força quando a lama invadiu a comunidade rural de Mariana e seguiu para dizimar o Rio Doce. A magnitude da destruição dos rejeitos da Samarco e, anos depois, da Vale, rasga à força o véu histórico de silêncio e complacência da mídia mineira (e da mídia nacional) com a mineração, tornando vozes dissonantes como a de Carlos Drummond de Andrade, conforme mostra Wisnik (2018), décadas depois, uma profecia distópica em processo de plena realização inconclusa.

Porém, quando esse silêncio é rompido, o que a mídia diz? Que discursos são construídos a partir das narrativas produzidas pelas coberturas jornalísticas dedicadas ao assunto? Quem diz na mídia? Percebemos que a cobertura hegemônica cotidiana dos principais jornais mineiros - aqui, em foco, O Tempo e Estado de Minas - reproduz e ajuda a construir o caráter técnico-corporativo do acontecimento, como se os protagonistas deste fossem a barragem, o talude, a cidade, e não as pessoas que podem morrer, que devem se salvar sozinhas (por viverem na infame denominação técnica de autossalvamento), que são forçadamente deslocadas de suas casas e suas rotinas por tempos indefinidos, o que configura uma demonstração de violência contra essas vidas marcadas pela insegurança. O referente deste acontecimento midiático, portanto, torna-se a própria mineração, e não os atingidos pela máquina minerária. A despeito das manchetes e das imagens, a verdadeira protagonista deste acontecimento é a mineração, o que configura uma hegemonia discursiva da mineradora Vale na cobertura jornalística dos dois veículos.

As marcas dos acontecimentos anteriores aparecem, nessa cobertura jornalística, de maneira bem sutil; não se apresentam na composição das matérias. Em que pese a potência narrativa do jornalismo, conforme já citado, nesta análise a cobertura mostrou-se circunscrita a uma situação bem específica, sem conexão com as ocorrências anteriores. Há um protagonismo do presente nas matérias veiculadas. Passado e futuro são temporalidades descartadas no material analisado.

$\mathrm{Na}$ segunda década do século XXI, o "destino mineral" mineiro aventado por Drummond parece se cumprir como nos versos de A máquina do mundo: “A treva mais estrita já pousara / sobre a estrada de Minas, pedregosa, / e a máquina do mundo, repelida, / se foi miudamente recompondo, / enquanto eu, avaliando o que perdera,/ seguia vagaroso, de mãos pensas". 


\section{REFERENCIAS}

BARROS, J. D’A. O tempo dos historiadores. Petrópolis: Vozes, 2013.

CASADEI, E. B. A. Construção de Personagens no Jornalismo: entre a matriz de verdade presumida e a imaginação das urdiduras de enredo. Ciberlegenda, v. 1, p. 77-91, 2010.

CASTELLS, M. O poder da identidade. (A era da informação: economia, sociedade e cultura volume 2). São Paulo: Paz e Terra, 1999.

DERRIDA, J. Demorar. Maurice Blanchot. Trad. Flavia Trocoli e Carla Rodrigues. Florianópolis, SC: Editora UFSC, 2015.

DEUZE, M.; W., T. O que o jornalismo está se tornando. Parágrafo. v. 4, n.2, p. 8-21, 2016.

Disponível em: http://revistaseletronicas.fiamfaam.br/index.php/recicofi/article/view/478/445 Acesso em: 02 mai 2019.

FERREIRA, P. Moradores fogem de Barão, e bombeiros ficam em alerta. O Tempo. Belo Horizonte, 26 mai. Cidades, p. 22, 2019.

Moradores doentes, bancos fechados e desamparo: Barão de Cocais vive o caos. O Tempo. Belo Horizonte, 2019. Disponível em: https://www.otempo.com.br/cidades/moradores-doentesbancos-fechados-e-desamparo-bar\%C3\%A3o-de-cocais-vive-o-caos-1.2185587 Acesso em: 25 jun 2019.

FRANÇA, V. V. O acontecimento e a mídia. Galaxia. São Paulo, n. 24, p. 10-21, dez, 2012. Disponível em <http://revistas.pucsp.br/index.php/galaxia/article/view/12939/9406> Acesso em: 5 mar. 2019.

LAGE, L. R. O testemunho do sofrimento como problema para as narrativas jornalísticas. In: Revista Contracampo, v. 27, n. 2, ed. ago-nov, ano 2013. Niterói: Contracampo. p. 71-88, 2013.

LE GUIN, U. K. A curva do sonho. São Paulo: Morro Branco, 2018.

LEAL, B. S. O jornalismo à luz das narrativas: deslocamentos. LEAL, Bruno S. e CARVALHO, C. A. de. (orgs.). Narrativas e poéticas midiáticas: estudos e perspectivas. São Paulo: Intermeios, 2013.

MENEZES, B. Tentativa de retomar a rotina. O Tempo. Belo Horizonte, 2 jun. Cidades, p. 22, 2019.

MOUILLAUD, M. Da forma ao sentido. In.: MOUILLAUD, Maurice; PORTO, Sérgio Dayrell (Orgs.). O jornal: da forma ao sentido. Brasília: Editora universidade de Brasília, p. 47-53, 2012.

PARREIRAS, M. Casal insiste em ficar. Estado de Minas. Belo Horizonte, 30 mai. Gerais, p. 15, 2019.

Dia de vigília e orações. Estado de Minas. Belo Horizonte, 27 mai. Gerais, p. 14, 2019.

PERES, A. C. Narrar o outro: notas sobre a centralidade do testemunho para as narrativas jornalísticas. Galaxia (São Paulo, Online), n. 31, p. 92-104, 2016.

QUERÉ, L. Entre facto e sentido: a dualidade do acontecimento. In Trajectos, número 6, pp. 59-75, 2005. 
A dupla vida do acontecimento: por um realismo pragmatista. In.: FRANÇA, Vera Regina Veiga; OLIVEIRA, Luciana de. (Orgs.). Acontecimento: reverberações. Belo Horizonte: Autêntica Editora, p. 21-38, 2012.

RODRIGUES, L. Barragens em risco deixam famílias desalojadas por tempo indeterminado. Agência Brasil, 2019. Disponível em: https://bit.ly/34Y8hvr. Acesso em: 8 dez. 2019.

RONAN, G. Distritos sentem impacto de obras. Estado de Minas. Belo Horizonte, 3 jun. Gerais, p. $15,2019$.

RONAN, G.; SILVA, C. Alento depois do susto. Estado de Minas. Belo Horizonte, 1 jun. Gerais, p. 14, 2019.

SILVA, G.; MAIA, F. D. Análise de cobertura jornalística: um protocolo metodológico. Rumores, v. 5, n. 10, p. 18-36, 2011.

SILVERSTONE, R. Por que estudar a mídia? São Paulo: Loyola, 2002.

SOUZA, C. Após alerta máximo, Vale diz que chance de barragem ruir reduziu. O Tempo. Belo Horizonte, 29 mai. Cidades, p. 21, 2019.

. Atingidos dizem que Vale quer minerar em Barão de Cocais. O Tempo. Belo Horizonte, 30 mai. Cidades, p. 28, 2019.

Parte de talude que caiu é menos de $1 \%$ de paredão que se move. O Tempo. Belo Horizonte, 1 jun. Cidades, p. 22, 2019.

TENENBOIM-WEINBLATT, K. Counting time: journalism and the temporal resource. In: Journalism and Memory. New York: Palgrave Macmillan UK, p. 97-112, 2014.

WISNIK, J. M. Maquinação do mundo - Drummond e a mineração. São Paulo: Companhia das Letras, 2018. 
Professor do curso de Jornalismo da Universidade Federal de Ouro Preto (UFOP). Doutorando em Teoria e Crítica Literária da Universidade Estadual de Campinas (Unicamp).

\section{Karina Gomes Barbosa}

Professora do curso de Jornalismo e do Programa de Pós-Graduação em Comunicação da Universidade Federal de Ouro Preto (UFOP). Doutora em Comunicação pela Universidade de Brasília (UnB).

Marta Regina Maia

Professora do programa de pós-graduação em Comunicação da Universidade Federal de Ouro Preto

(UFOP). Doutora em Ciências da Comunicação pela Universidade de São Paulo (USP), com pós-doutoramento em Comunicação pela Universidade Federal de Minas Gerais (UFMG).

\section{@(ఠ)}

Esta obra está licenciada com uma Licença Creative Commons Atribuição-NãoComercial-CompartilhaIgual 4.0 Internacional 